\title{
Developing a training program to develop the competency of regional operating officers (ROO) in a virtual service provider office (VSPO) in Thailand
}

\author{
P. Boonda ${ }^{1}$ \& A. Preedeekul ${ }^{2}$ \\ ${ }^{1}$ Sirindhorn College of Public Health, Thailand \\ ${ }^{2}$ Department of Curriculum and Instruction Faculty of Education, \\ Pibulsongkram Rajabhat University, Thailand
}

\begin{abstract}
The purpose of this study was to develop a training program to develop the competency of ROO in a VSPO in Thailand which was conducted in four stages as follows: (1) the study and review of virtual regional office models, (2) analysis and synthesis, the first stage and then creation and justification, a model, (3) implementation by training, and (4) evaluation. The research found that the training program was composed of four modules as follows: (1) Health Sector Reform and Regional Health System; (2) Management, Leadership, and Partnership for Regional Health; (3) Competency of ROO; and (4) Field Study. The results of achievements after training showed that the knowledge of the practitioners who were trained at competency level 1 had improved from $75.00 \%$ to $88.35 \%$. The knowledge of the practitioners at level 2 increased from $82.50 \%$ to $87.50 \%$. The achievement of skills by behavioral observation suggested that the practitioners at level 1 had increased their skills from $50.30 \%$ to $75.00 \%$. The practitioners at level 2 increased their skills from $60.50 \%$ to $79.50 \%$. An evaluation of productivity before and after the training program for three major elements found that SWOT analysis increased from $76.69 \%$ to $96.78 \%$, determination strategies from $86.86 \%$ to $98.25 \%$, and finally transformation strategies to action plan from $80.52 \%$ to $95.64 \%$. It can be confidently concluded that this program was developed with considerable applicability to other offices. Keywords: training program, regional operating officer, virtual office, service provider office.
\end{abstract}




\section{Introduction}

The Ministry of Health has the main responsibility of promoting public health by providing a comprehensive health-care system and health promotion, prevention, and treatment. It is also needs to make sure that the limited available resources are used efficiently and potential health-care problems within the public health system in the region are anticipated and addressed. As a result, a policy in developing all levels of the health-care system is established. A health service system development plan is created to develop a network service under the principle of "seamless services network" link service to meet the health needs of the country.

In 2013, efforts to reform the health system started with the aim of optimizing the management of the health system of the country, improving the management style in the area providing health services in the 12 regions, and promoting solidarity in the management and services of the health services network.

In 2014, the Second Regional Health Service is one of the country's 12 service network zones, which is defined for virtual service provider office (VSPO) and responsible for the Tak, Phitsanulok, Sukhothai, Uttaradit, and Phetchabun provinces [1]. This is similar to having a virtual enterprise, but no clear model operates in a virtual organization and there is no clear format appropriate to the context. As a virtual organization, it is a new form of organization challenged to bring the application but not the definition that is generally accepted by the virtual organization seen 15 to 20 years ago, when working from home was made possible by the use of technology $[2,3]$. Since then, terms such as virtual office, virtual classroom, and virtual corporation have appeared in the literature [4-6].

The VSPO management model (VSPOMM) of the Second Regional Health Service in Thailand is composed of seven factors from 46 selected variables as follows: (1) providing administration and management for everyone, regardless of time and place, as media and technologies fit in any way; (2) establishing administration by collaboration and clearing house; (3) supporting technical services both in the system and outside the system in academic administration; (4) instituting stakeholder support system in the network of general administration; (5) freedom in budget administration, especially in information technology development; (6) personnel administration with new management and information technology skills; and (7) operating support resources management, including management cockpit, document and URL web link, and using web technology applications [1]. They put into consideration the concept of virtual reality created by a computer to establish an organization, so it may be of no physical shape, which is a characteristic that is different from traditional organizations in general. However, the definition of virtual organizations refers to the network of organizations linked by information technology to share operational skills and resources [7] through the use of telecommunications, technology, social, and community networks, which are interdependent cooperation, flexibility, trust, and self-organization [8]. The scope of the organization has an unclear boundary and location, which is expected to be useful in the adoption of VSPOMM for service plan (SP) and in performing effectively. 
VSPO is a new key management mechanism created to realize the health service system development plans and also a mechanism established to bring about the integration of all elements of the health system. However, this VSPO to support the work of the executive has not yet been formally operations practitioners deployed and there are no training programs yet, which are necessary to develop the competency of regional operating officers (ROO) in each province. The purpose of this study was to create a training program to develop the competency (knowledge, skill, and practice for service plan administration) of ROO in a VSPO in Thailand. Researchers are interested in creating a new training program to develop the competency of ROO in a VSPO, which is a new organizational model to solve the above-mentioned problems.

\section{Materials and methods}

\subsection{Research objective}

To develop a training program by analyzing four methods: 1) Content analysis; 2) Components of variable analysis by exploratory factor analysis (EFA); 3) Core components of variable analysis by second-order confirmatory factor analysis (CFA); and 4) Using descriptive statistics.

\subsection{Hypotheses}

1) The variables used in this study can access the elements of the training program factors to develop the competency of ROO in a VSPO in Thailand; 2) The developed model has the precision of the second-order CFA of the training program factors to develop the competency of ROO in a VSPO in Thailand; and 3) A model was considered by stakeholders for use in human resource development.

\subsection{Data sources}

Experts, executives, and practitioners in the Vice Chief of the Provincial Health Office were selected for the training program. Groups studied in this research were selected by stratification and purposive sampling. They are those who have a deep understanding about the executive office of health services or those who are used to performing tasks related to health services, including in field offices.

Population: Experts, executives on various aspects, and practitioners in the Vice Chief of the Provincial Health Office in the Second Regional Health Service (Phitsanulok, Tak, Uttaradit, Sukhothai, and Phetchabun). Sample: Experts ( $\mathrm{n}=20)$ were selected by purposive sampling; executives $(\mathrm{n}=664)$ were selected by stratification sampling from the country's 12 service network zones; and practitioners in the Vice Chief of the Provincial Health Office (ROO) in the five provinces, five for each province $(\mathrm{n}=25)$ (Phitsanulok, Tak, Uttaradit, Sukhothai, and Phetchabun), were selected by purposive sampling. 


\subsection{Research process}

The purpose of this study was to create a training program to develop the competency of ROO in a VSPO in Thailand using mixed methods of research and development. The study was conducted in four stages as follows:

Step 1: Study of the information about the training program to develop the competency by investigating various data sources, including textbooks, research databases, and the Internet, both domestic and foreign.

Step 2: Analysis and synthesis of the components of structure in the VSPOMM from the data of Step 1 and 20 experts as follows: (1) philosophy, vision, principles, mission statement, policies, goals, and objectives; (2) administration established for the VSPOMM for SP; (3) academic administration; (4) general administration; (5) administrative budget; (6) administrative personnel; and (7) resources to support the work of health services to serve as a basis for the design training program. Then, the components of a new training program were created. The elements considered are as follows: (1) health sector reforms; (2) regional health system; (3) new management; (4) leadership; (5) partnership for regional health; (6) competency of the regional officer; and (7) field learning. Subsequently, this has brought both elements of structure and training program using the structural equation model (SEM), which is developed by two elements:

1. Experts who created the master of studies and research-related documents and then used it as a framework to create a query. The survey collected the data from a sample of experts and analyzed it with EFA.

2. CFA, which introduces elements that are developed by experts in the framework of item 1 to create a query, and a questionnaire to collect data from 664 executives and practitioners who were asked about their opinions on the details of health sector reforms, regional health system, new management, leadership, partnership for regional health, competency of the regional officer, and field learning in the 12 regions of VSPO of the regional health service in Thailand, and then analyzed with the second-order CFA.

Then, a new training program to develop the competency of ROO in a VSPO in Thailand using the Delphi technique, which includes three rounds of data gathering of the opinions of 20 experts, was created. In the first round of data collection using questionnaire scales with five levels, the experts were asked about their opinions on the details of health sector reforms, regional health system, new management, leadership, partnership for regional health, competency of the regional officer, and field learning. The mean, median, and interquartile range (IR) of the responses were computed and presented for data analysis. The experts compared their answers to the answers of the group in the second and third rounds for review and comment. Then, the optimal training program to develop the competency of ROO in a VSPO in Thailand using the Delphi technique for data collection of 20 high executives was determined.

Step 3: Implementation using the various practitioners in the Vice Chief of the Provincial Health Office in five provinces ( 25 people) who attended the training courses of the field practitioners of the province. The training program was 
presented with four modules in the following order: (1) Module 1: Health Sector Reform and Regional Health System (two elements); (2) Module 2: Management, Leadership, and Partnership for Regional Health (two elements); (3) Module 3: Competency of ROO (four elements); and (4) Module 4: Field Study (two elements).

Step 4: Evaluation by 10 executives (service provider board) who managed the VSPO of the Ministry of Public Health in Thailand.

\subsection{Statistical analysis}

Data were analyzed using SPSS and AMOS for Windows. Several statistics were derived, including percentage, mean, median, IR, EFA, second-order CFA.

\section{Results}

\subsection{Analyzing the VSPOMM factors for SP in the regional health service in Thailand using EFA and the 2nd order CFA}

The results of EFA for testing the suitability of the variables used in this study were analyzed using Kaiser-Meyer-Olkin (KMO) Measure of Sampling Adequacy. The results showed that the KMO of MSA was 0.890 , which exceeds 0.80 , indicating that the variable series is appropriate to be analyzed at a good level on the basis of Kim and Mueller [9]. Moreover, the Bartlett's test of sphericity [10] found that the variables correlated significantly $(\mathrm{p}=0.000)$, which shows that different variables can be used to analyze the elements. Results of the 2nd Order CFA are analyzed to confirm that the 10 elements are classified as major elements of the four aspects as detailed in Figure 1 and Table 1.

Table 1: $\quad$ Statistics measuring the harmony of the model with empirical data of the VSPOMM for SP factors in the regional health service in Thailand.

\begin{tabular}{lcccc}
\hline \multicolumn{1}{c}{ Fit index } & Acceptable threshold levels & $\begin{array}{c}\text { The } \\
\text { values } \\
\text { obtained }\end{array}$ & Consideration & Decision \\
& $>0.05$ & 0.076 & Meet the criteria & Well \\
\hline Chi-square $\left(\chi^{2}\right)$ & $<2.00$ & 1.471 & Meet the criteria & Well \\
CMIN/DF & $>0.90$ & 0.991 & Meet the criteria & Well \\
GFI & $>0.90$ & 0.976 & Meet the criteria & Well \\
AGFI & $<$ ECVI for saturated model $(0.290)$ & 0.166 & Meet the criteria & Well \\
ECVI & $>$ Saturated AIC $(110.00)$ & 110.00 & Meet the criteria & Well \\
Model AIC & $>0.90$ & 0.994 & Meet the criteria & Well \\
NFI & $>0.90$ & 0.998 & Meet the criteria & Well \\
CFI & $<0.05$ & 0.006 & Meet the criteria & Well \\
RMR & $<0.05$ & 0.027 & Meet the criteria & Well \\
RMSEA & L &
\end{tabular}

AGFI, adjusted goodness-of-fit index; AIC, Akaike information criterion; CFI, comparative fit index; CMIN/DF, $\chi^{2}$ statistics and degrees of freedom ratio; ECVI, expected crossvalidation index; GFI, goodness-of-fit index; NFI, normed-fit index; RMR, root mean square residual; RMSEA, root mean square error of approximation. 


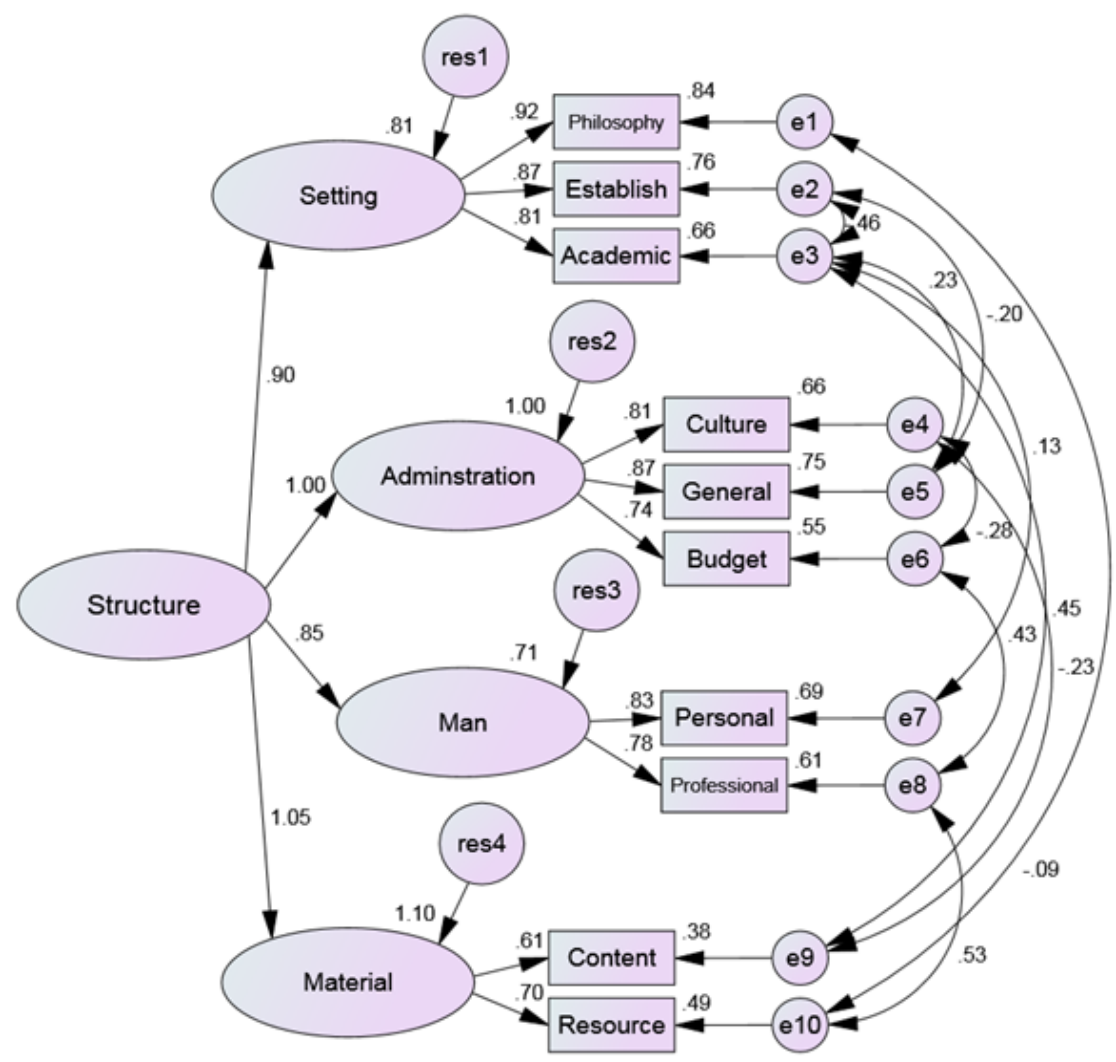

Figure 1: The second confirmatory factor model of the VSPOMM for SP factors in the regional health service in the regional health service in Thailand.

Figure 1 and Table 1 found that the model element of VSPOMM for SP factors in the regional health service in Thailand is desirable and consistent with the empirical data of the administrators and practitioners due to a statistical measure of harmony through them, showing that the model has good construct validity. It can be seen that the VSPOMM for SP factors in the regional health service in Thailand is desirable, as it includes the four aspects: (1) tools to support the work of health services (two elements), (2) general management (three elements), (3) framework for the establishment of the health service virtual office (three elements), and (4) administrative staff (two elements). There is a total of 10 components: (1) resource (operating support resources management), (2) content (developing academic subject), (3) general (general administration), (4) culture (building culture), (5) budget (budget administration), (6) philosophy (philosophy, methodology), (7) establish (establishing an office management model with virtualization), (8) academic (academic administration), (9) personnel (personnel 
administration), and (10) professional (personnel who have a professional background).

\subsection{Analyzing the training program factors to develop competency of ROOs in the VSPO in Thailand [11]}

The results of EFA for testing the suitability of the variables used in this study were analyzed using the KMO Measure of Sampling Adequacy. The results showed that the KMO of MSA was 0.959 , which exceeds 0.80 , showing that the variable series is appropriate to be analyzed at a good level on the basis of Kim and Mueller [9]. Moreover, Bartlett's test of sphericity [10] found that the variables correlated significantly $(\mathrm{p}=0.000)$, which shows that different variables can be used to analyze the elements. Results of the 2nd Order CFA are analyzed to confirm that the 4 elements are the four aspects as detailed in Figure 2 and Table 2.

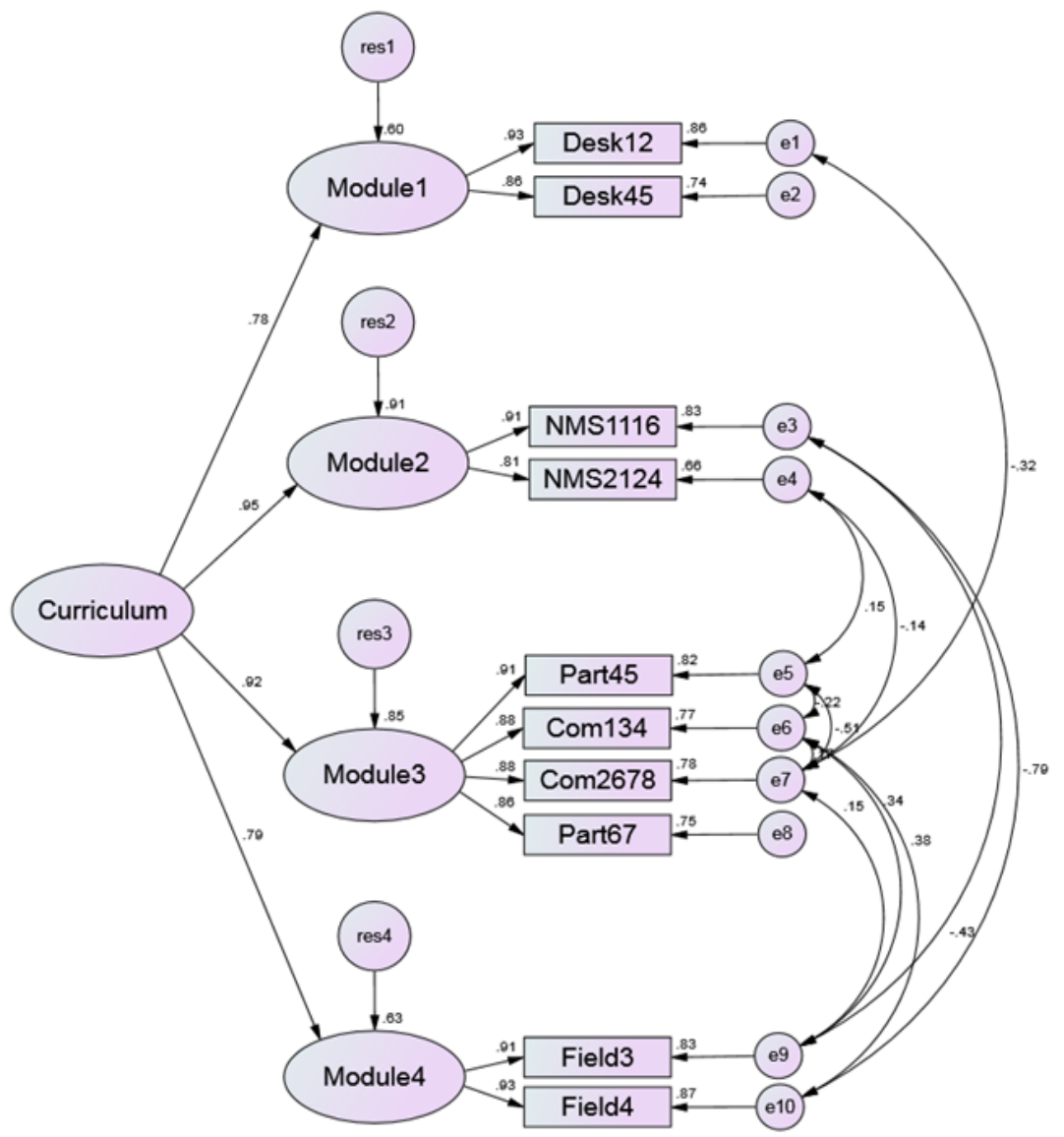

Figure 2: The 2nd order CFA model of the training program factors to develop competency of ROO in the VSPO in Thailand. 
Table 2: $\quad$ Statistics measuring the harmony of the model with empirical data of the Training Program Factors to Develop Competency of ROO in the VSPO in Thailand.

\begin{tabular}{lcclc}
\hline Fit index & Acceptable threshold levels & $\begin{array}{c}\text { The values } \\
\text { obtained }\end{array}$ & Consideration & Decision \\
\hline Chi-square & $>0.05$ & 0.055 & Meet the criteria & Well \\
$\left(\chi^{2}\right)$ & & & & \\
CMIN/DF & $>2.00$ & 1.550 & Meet the criteria & Well \\
GFI & $>0.90$ & 0.991 & Meet the criteria & Well \\
AGFI & $>0.90$ & 0.975 & Meet the criteria & Well \\
ECVI & $<$ ECVI for saturated model $(0.290)$ & 0.166 & Meet the criteria & Well \\
Model AIC & $<$ Saturated AIC $(110.00)$ & 110.00 & Meet the criteria & Well \\
NFI & $>0.90$ & 0.995 & Meet the criteria & Well \\
CFI & $>0.90$ & 0.998 & Meet the criteria & Well \\
RMR & $<0.05$ & 0.008 & Meet the criteria & Well \\
RMSEA & $<0.05$ & 0.029 & Meet the criteria & Well \\
\hline
\end{tabular}

Table 2 and Figure 2 found that the model element of the training program factors to develop the competency of ROO in a VSPO in Thailand is desirable and consistent with the empirical data of the administrators and practitioners due to a statistical measure of harmony through them, showing that the model has good construct validity. It can be seen that the training program factors to develop the competency of ROO in a VSPO in Thailand is desirable, as it includes the four aspects: (1) Module 1: Health Sector Reform and Regional Health System (two elements); (2) Module 2: Management, Leadership, and Partnership for Regional Health (two elements); (3) Module 3: Competency of ROO (four elements); and (4) Module 4: Field Study (two elements). There is a total of 10 components: (1) Desk12 (service plan and personnel administration), (2) desk45 (fiscal and monetary, internal control and risk management), (3) nms1116 (new management skills, system thinking, analytical thinking, synthesis thinking, conflict management part 1, leadership), (4) nms2124 (positive thinking, conflict management part 2, negotiation skill contingency management), (5) part 45 (network management, team building), (6) part67 (project management, monitoring and data definition), (7) com134 (presentation of methods and data for monitoring, presentation skill, conference management skill), (8) com2678 (researching, learning skill, communication skill exercise, action plan workshop, preparation to study in the field workshop), (9) field 3 (summary to adjust strategies, KPI, and action plan), and (10) field 4 (summary to present for administrators in the VSPO).

\subsection{Results of training program}

Developing this training program to develop the competency of ROO in a VSPO in Thailand beginning from steps 1 and 2 in the research process includes studying the data and information, analysis and synthesis of the components of structure 
in the VSPOMM for SP from data and experts, and then creation of the components of a new training program. Subsequently, this has brought both the elements of structure and training program analyzed by SEM, which is developed by two elements: (1) EFA and (2) second-order CFA. The results of the second-order CFA from the data of the administrators and practitioners in the VSPO in the regional health service in Thailand indicated that the elements of the training program that include four aspects of main elements and 10 sub-elements have good construct validity. Because the model is consistent with the empirical data, it is in good shape. Then, new training program to develop the competency of ROO in a VSPO in Thailand was created and the optimal training program to develop the competency of ROO in a VSPO in Thailand was determined. The results of the training program to develop the competency of ROO in a VSPO in Thailand are presented with four modules in the following order: (1) Module 1: Health Sector Reform and Regional Health System; (2) Module 2: Management, Leadership, and Partnership for Regional Health; (3) Module 3: Competency of ROO; and (4) Module 4: Field Study as detailed in Table 3.

Table 3: Structure of the training program factors to develop competency of ROO in the VSPO in Thailand.

\begin{tabular}{|c|c|c|}
\hline & Side & Core component \\
\hline 1) & MODULE1 & $\begin{array}{l}\text { 1. Service Plan and Personnel Administration } \\
\text { 2. Fiscal and Monetary, Internal Control and Risk } \\
\text { Management }\end{array}$ \\
\hline 2) & MODULE2 & $\begin{array}{l}\text { 3. New management skills, System Thinking, Analytical } \\
\text { Thinking, Synthesis Thinking, Conflict Management } \\
\text { part 1, Leadership } \\
\text { 4. Positive Thinking, Conflict Management part 2, } \\
\text { Negotiation Skill Contingency Management }\end{array}$ \\
\hline 3) & MODULE3 & $\begin{array}{l}\text { 5. Network Management, Team Building } \\
\text { 6. Project Management, Monitoring and data definition } \\
\text { 7. Presentation of Methods and Data for monitoring, } \\
\text { Presentation skill, Conference management skill } \\
\text { 8. Researching, learning skill, Communication skill exercise, } \\
\text { Action plan work shop, Preparation to study in the fields } \\
\text { work shop }\end{array}$ \\
\hline 4) & MODULE4 & $\begin{array}{l}\text { 9. Summary to adjust Strategies, KPI and Action Plan } \\
\text { 10. Summary to present for Administrators in the VSPO }\end{array}$ \\
\hline
\end{tabular}

The results of the data analysis and the opinions of the practitioners in the Vice Chief of the Provincial Health Office in the Second Regional Health Service and the executives in all the provinces in Thailand about training in steps 3 and 4 found that most practitioners and executives agreed on most issues of the four modules.

The results of achievements after training showed that the knowledge of the practitioners who were trained at competency level 1 had improved from $75.00 \%$ to $88.35 \%$. The knowledge of the practitioners at level 2 increased from $82.50 \%$ 
to $87.50 \%$. The achievement of skills by behavioral observation suggested that the practitioners at level 1 had increased their skills from $50.30 \%$ to $75.00 \%$. The practitioners at level 2 increased their skills from $60.50 \%$ to $79.50 \%$. An evaluation of productivity from group process and report before and after the training program for three major elements found that SWOT analysis increased from $76.69 \%$ to $96.78 \%$, determination strategies from $86.86 \%$ to $98.25 \%$, and finally transformation strategies to action plan from $80.52 \%$ to $95.64 \%$.

\section{Discussion and conclusion}

The results of developing a training program to develop the competency of ROO in a VSPO in Thailand, which practitioners and executives agreed with the points on four modules, found that the course focused on adult learning and active learning, which the participants agreed that the course is appropriate and useful, can be applied better. This is in response to VSPO, which is a new key management mechanism created to realize the health service system development plans and also a mechanism established to bring about the integration of all elements of the health system that is composed of seven factors. These components of variables were analyzed by EFA and second-order CFA to use as a basis of the training program design by creating the components of a new training program. The elements considered are as follows: (1) health sector reforms, (2) regional health system, (3) new management, (4) leadership, (5) partnership for regional health, (6) competency of the regional officer, and (7) field learning. Then, the optimal training program was determined.

In the part of the effectiveness of the training program to develop the competency of ROO in a VSPO in Thailand, achievement evaluation of knowledge, skills, and practices by facilitators and self-assessment of the performance of public administration as well as follow-up comments in a meeting with the trainees found the following results: 1) The role and performance management of the participants before and after the training program have different average scores, which showed statistically significant difference $(\mathrm{P}<0.05)$. In terms of the facilitator role, mentor role, innovator role, broker role, producer role, director role, and coordinator role, the average scores of the monitor role were statistically insignificant difference $(\mathrm{P}>0.05)$. The role of the regulator that seems like a watchful and intrusive gaze means supervision, and snooping seems like a controlling or nosy activity but is an act to maintain the high performance of the personnel and team. Depending on who is trained, there are a variety of positions, not working directly in the VSPO and not the role full potential because it does not mandate directly. 2) The desirable competencies of ROO in the VSPO equivalent to middle-level public health administrators in eight aspects are (1) achievement orientation, (2) good service, (3) accumulating expertise in careers but focusing on the knowledge broker, (4) virtue ethics and dignity, (5) cooperation, (6) systems thinking: creative but focusing on the system experts, (7) consciousness of living based on the sufficiency, and (8) building alliances in the management but focusing on communication technology and information. The average comparison before and after the training program in the 
eight performances showed statistically significant difference $(\mathrm{P}<0.05)$. This might be due to the training model, activities to promote teamwork, creating a supportive network mutual help, and teamwork. Learning portfolio is an exchange between members with similar properties. It is an important platform that complements the knowledge and exchange experiences in view of the development of responsibility for the virtual organization.

A reflection of the views from people outside the organization (outside in) helps promote sustainability expertise. In addition, the performance of ROO in the VSPO equivalent to middle-level public health executives in eight aspects is a needed feature of the Ministry of Public Health that administrators at all levels must have developed. Compliance with various executives includes basic, intermediate, and advanced levels. The issue is about the awareness of who is trained.

Suggestions of research findings: 1) The Ministry of Public Health should take this course as a basis for the development of personnel management to move to a higher level. 2) Public health executives can be further developed in various senior management roles. 3) Executives can use this information to consider selecting individuals to move higher or to evaluate the performance for development. 4) Units for the executive development courses can be adapted to suit with the context and the culture of each organization or guideline development organizations. 5) Agencies and organizations can be used as an impurity in enhancing performance management. Suggestions of a direct connection: 1) Monitoring ROO who were trained in the VSPO. 2) Evaluation of the course in a study group and a control group using experimental research methods. 3) A study of leadership development with a new variety.

It can be confidently concluded that the training program to develop the competency of ROO in a VSPO was developed with considerable applicability to other service provider offices. The development of the training program must be analyzed using the four methods of research and development. In principle, these are analyzing the contents by studying and reviewing the virtual regional office models from related documents and literatures to use in designing a questionnaire(s) that will collect data from stakeholders for the analysis and synthesis of the components of the office structure, which will serve as a basis for the design training program, and then creation of the components of a new training program. Subsequently, this has brought both the elements of structure and training program analyzed by SEM, which is developed by two elements: EFA and second-order CFA. Both EFA and second-order CFA assist in the extraction of the variables, which will make possible all the important variables of the organizational structure and training programs. As a result, the program has trained credible ROO. Then, a new training program to develop the competency of ROO in a VSPO in Thailand using the Delphi technique is created. Finally, testing and evaluation will follow, whereas training with formative and summative evaluation is done at the end of training. 


\section{References}

[1] Boonda, P., Markmee, P., Preedeekul, A., Nissayan, J., Saksripanich, S., Developing an appropriate Virtual Service Provider Office Management Model for Service Plan in the Second Regional Health Service of Ministry of Public Health in Thailand. In Proceedings of Second International Conference on Global Public Health 2014; Jul 3-4; Negombo, Sri Lanka, pp. 54-59, 2014.

[2] Olson, MH., Remote office work: changing work patterns in space and time. Communications of the ACM, 26(3), pp. 182-187, 1983.

[3] Venkatesh, A., Vitalari, N., An emerging distributed work arrangement: an investigation of computer-based supplemental work at home. Management Science, 38(12), pp. 1687-1706, 1992.

[4] Giuliano, VE., The mechanization of office work, Scientific American, 247, pp. 149-164, 1982.

[5] Hiltz, SR., The virtual classroom: using computer mediated communication for university teaching. Journal of Communication, 36: 95-104, 1986.

[6] Malone, M., Davidow, W., Virtual Corporation. Forbes, 150, pp. 102-107, 1992.

[7] Travica, B., The Design of the Virtual Organization: A Research Model. In Proceedings of the American Conference on Information Systems; August 15-17; Indianapolis: AIS, pp. 417-419, 1997.

[8] Faucheux, Claude, How Virtual Organizing is Transforming Management Science, Communication of the ACM, 40(9), pp. 50-55, 1997.

[9] Jae-On Kim, Charles W. Mueller., Introduction to factor analysis: what it is and how to do it. Beverly Hills, Calif.: Sage Publications; 1978.

[10] Barrett, P., Structural Equation Modeling: Adjudging Model Fit, Personality and Individual Differences, 42 (5), pp. 815-824, 2007.

[11] Boonda P., Preedeekul A., Markmee P., Developing of Training Program Factors to Develop Competency of Regional Operating Officer (ROO) in the Virtual Service Provider Office (VSPO) in Thailand, In Proceedings of Sixth Asia-Pacific Conference on Public Health (APCPH); Aug 23-26; Bangkok, Thailand, 2016. 